\title{
Potential Deleterious Effects of Vasopressin in Chronic Kidney Disease and Particularly Autosomal Dominant Polycystic Kidney Disease
}

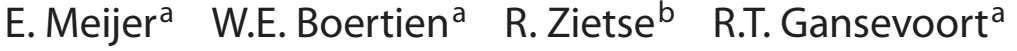 \\ a Division of Nephrology, Department of Internal Medicine, University Medical Center Groningen, University of \\ Groningen, Groningen, and b Department of Nephrology, Erasmus Medical Center, Rotterdam, The Netherlands
}

\section{Key Words}

Vasopressin • Copeptin • Chronic kidney disease •

Autosomal dominant polycystic kidney disease •

Albuminuria Proteinuria $\cdot$ Glomerular filtration rate

\begin{abstract}
The antidiuretic hormone vasopressin is crucial for regulating free water clearance in normal physiology. However, it has also been hypothesized that vasopressin has deleterious effects on the kidney. Vasopressin is elevated in animals and patients with chronic kidney disease. Suppression of vasopressin activity reduces proteinuria, renal hypertrophy, glomerulosclerosis and tubulointerstitial fibrosis in animal models. The potential detrimental influence of vasopressin is probably mediated by its effects on mesangial cell proliferation, renin secretion, renal hemodynamics, and blood pressure. In this review, we discuss the increasing body of evidence pointing towards the contribution of vasopressin to chronic kidney disease progression in general and to autosomal dominant polycystic kidney disease in particular. These data allude to the possibility that interventions directed at lowering vasopressin activity, for example by the administration of vasopressin receptor antagonists or by drinking more water, may be beneficial in chronic kidney disease.
\end{abstract}

Copyright ๑ 2011 S. Karger AG, Basel

KARGER
Fax +41 61306 1234
E-Mail karger@karger.ch
www.karger.com

C 2011 S. Karger AG, Basel

$1420-4096 / 11 / 0344-0235 \$ 38.00 / 0$

Accessible online at:

www.karger.com/kbr

\section{Introduction}

Vasopressin is a nonapeptide hormone that is derived from a precursor synthesized in the hypothalamus. It is transported to the pituitary gland, where it is secreted in reaction to an increase in plasma osmolarity and a decrease in effective circulating volume [1]. Vasopressin is also synthesized in response to stress. There are three receptor subtypes known that can bind vasopressin, the V1a, V1b and V2 receptors. The V1a and V2 receptors mediate a number of different cellular effects, many of which are part of a response leading to water conservation. The V1a receptor is localized in smooth muscle cells, the liver and the kidney. In the kidney, the V1a receptor is mainly localized in the interlobular arteries, the descending vasa recta, the macula densa and the collecting duct [2]. Activation of the V1a receptor results in an increase in blood pressure by vasoconstriction. This increased vasoconstriction is the result of a direct effect on smooth muscle cells and of an indirect effect caused by increased renin secretion [3]. A complex interplay between V1a- and V2-receptor-mediated effects has been suggested $[4,5]$. The V1b receptor is located in the adenohypophysis. Activation results in ACTH and subsequent cortisol release. This receptor is considered important for temperature regulation, memory and especially the stress response $[6,7]$. The V2 receptor is found in the kidney 
and is predominantly localized in the collecting duct, but also in the macula densa and the thick ascending limb of Henle. Stimulation of the V2 receptor by vasopressin increases water reabsorption primarily by inserting aquaporin-2 water channels into the apical cell membrane of the collecting duct. Furthermore, it also increases urea reabsorption through the urea transporters UTA1 and UTA3. Sodium reabsorption is increased by a dose-dependent V2-receptor-mediated effect of vasopressin on the $\mathrm{Na}-\mathrm{K}-\mathrm{Cl}$ cotransporter in the thick ascending limb of Henle, on the $\mathrm{Na}-\mathrm{Cl}$ cotransporter in the distal convoluted tubule [8] and, most importantly, on the epithelial sodium channel in the principal cells of the collecting duct [9]. Vasopressin V2 receptor activation thus not only increases free water permeability of the collecting duct, but also regulates medullary osmolarity, the driving force of water reabsorption. Subjects who lack vasopressin (central diabetes insipidus) or are insensitive to vasopressin (nephrogenic diabetes insipidus) have to drink large volumes of water to prevent dehydration, illustrating the physiologic importance of vasopressin.

\section{Potential Deleterious Renal Effects of Vasopressin}

\section{Mechanisms}

Although vasopressin has a pivotal role in normal physiology, it has been hypothesized that in certain circumstances vasopressin may also have deleterious effects on the kidney. Vasopressin is described to negatively affect renal hemodynamics by increasing glomerular filtration rate (GFR) by two different mechanisms. Both mechanisms might induce glomerular hyperfiltration on the short term. On the long term, this hyperfiltration will be detrimental. It has been postulated that intrarenal recycling of urea, triggered by vasopressin, might influence GFR adversely by modifying the composition of the tubular fluid at the macula densa, thus affecting the intensity of the tubuloglomerular feedback control of GFR [1012]. Vasopressin could furthermore potentially stimulate the renin-angiotensin-aldosterone system directly because of the presence of V1a and V2 receptors in the macula densa.

Under physiological conditions, the renal vasculature and total renal blood flow are relatively insensitive to the action of vasopressin on the V1a receptor. However, in pathological conditions, a renal vasoconstrictor response is observed. In addition, vasopressin could theoretically induce hypertension by a direct effect on vascular smooth muscle through activation of the Vla receptor, or indi- rectly by V2 receptor-mediated increased tubular sodium retention $[5,13]$. On the other hand, some have suggested that hypertension will be attenuated by vasodilation due to prostaglandin release through Vla activation. Lastly, vasopressin has been suggested to exert direct effects on proliferation of mesangial cells and renal hypertrophy, production of collagen and fibronectin and inhibition of matrix metalloproteinase-2 $[14,15]$. In summary, vasopressin may have deleterious effects on the kidney by causing increased glomerular pressure, renin release, hypertension and mesangial cell proliferation.

\section{Experimental Evidence}

Several observations in experimental studies are in line with a deleterious role for vasopressin in chronic kidney disease (CKD). First, spontaneous vasopressin levels have been found to be elevated in animal models with CKD $[16,17]$. Second, administration of DDAVP (1-desamino-8-D-arginine vasopressin or desmopressin, a vasopressin V2 receptor agonist) increased proteinuria and worsened renal function after 5/6 nephrectomy in Brattleboro rats, that are characterized by a genetically determined vasopressin deficiency [18]. Deleterious effects were also observed in other models. Continuous administration of desmopressin to rats, resulting in an experimental SIADH (syndrome of inappropriate antidiuretic hormone secretion) model, induced renal histopathologic abnormalities, such as dilatation of tubules, and inflammatory cell infiltration, accompanied by significant increases in the relative weight of the kidney [19]. Desmopressin administration in uninephrectomized DOCA-salt hypertensive rats (a model for salt-dependent nonmalignant hypertension) led to worsening of hypertension and renal histology and an increase in albuminuria [20]. Third, inhibition of vasopressin activity ameliorates renal disease in CKD animal models. In an experiment in rats with 5/6 nephrectomy, vasopressin activity was suppressed by adding water to the chow of these animals, thus inducing a high water intake. After 5 weeks of high water intake, these rats had a lower percentage of glomeruli with segmental lesions than rats that received normal water intake [16]. In another study in rats with 5/6 nephrectomy, urinary volume increased and urinary osmolarity decreased after the nephrectomy, suggesting impaired renal urinary concentrating capacity. Vasopressin levels were found to be elevated compared to control rats. When rats were forced to a high water intake, vasopressin levels decreased, and blood pressure, proteinuria and plasma creatinine were reduced [17]. When 5/6 nephrectomy is performed in genetically vasopressin-deficient 
Table 1. Experimental studies investigating a renal protective role of vasopressin receptor antagonists in CKD (adapted from Torres et al. [21])

\begin{tabular}{|c|c|c|c|}
\hline Study & Class of drug & Animal model & Results \\
\hline $\begin{array}{l}\text { Okada et al. } \\
{[22], 1994}\end{array}$ & V1aRA, V2RA & DOCA-salt- and Adriamycin-treated rats & $\begin{array}{l}\text { both reduced blood pressure rise, the } \\
\text { combination ameliorated histology }\end{array}$ \\
\hline $\begin{array}{l}\text { Okada et al. } \\
{[23], 1995}\end{array}$ & V1aRA, V2RA & $\begin{array}{l}\text { uninephrectomized DOCA-salt } \\
\text { hypertensive rats }\end{array}$ & V2RA and combination reduced blood pressure \\
\hline $\begin{array}{l}\text { Okada et al. } \\
{[24], 1995}\end{array}$ & V1aRA, V2RA & 5/6 nephrectomized SHR & $\begin{array}{l}\text { both reduced proteinuria, proteinuria and } \\
\text { arteriosclerosis }\end{array}$ \\
\hline $\begin{array}{l}\text { Okada et al. } \\
{[25], 1996}\end{array}$ & V1aRA, V2RA & Adriamycin-treated rats & $\begin{array}{l}\text { both reduced proteinuria and histologic } \\
\text { alterations }\end{array}$ \\
\hline $\begin{array}{l}\text { Kurihara et al. } \\
{[26], 1996}\end{array}$ & V1aRA & uninephrectomized SHR & $\begin{array}{l}\text { reduced blood pressure, glomerular sclerosis } \\
\text { and improved renal function }\end{array}$ \\
\hline $\begin{array}{l}\text { Windt et al. } \\
{[28], 2006}\end{array}$ & V1aRA & $\begin{array}{l}5 / 6 \text { nephrectomized rats, starting } 2 \text { weeks } \\
\text { after surgery }\end{array}$ & reduced proteinuria and glomerular sclerosis \\
\hline $\begin{array}{l}\text { Windt et al. } \\
{[28], 2006}\end{array}$ & V1aRA & $\begin{array}{l}\text { 5/ } 6 \text { nephrectomized rats, starting } 6 \text { weeks } \\
\text { after surgery }\end{array}$ & no effect \\
\hline $\begin{array}{l}\text { Okada et al. } \\
{[29], 2009}\end{array}$ & V2RA & puromycin aminonucleoside nephrosis & $\begin{array}{l}\text { reduced proteinuria and kidney weight and } \\
\text { improved renal function }\end{array}$ \\
\hline $\begin{array}{l}\text { Perico et al. } \\
\text { [30], } 2009\end{array}$ & V1a/V2RA & $5 / 6$ nephrectomized rats & $\begin{array}{l}\text { reduced hypertension, proteinuria and } \\
\text { glomerular sclerosis }\end{array}$ \\
\hline
\end{tabular}

$\mathrm{V}=$ Vasopressin; $\mathrm{RA}$ = receptor antagonist; DOCA = deoxycorticosterone acetate; $\mathrm{SHR}=$ spontaneously hypertensive rats.

Brattleboro rats, compensatory renal hypertrophy and CKD progression were attenuated when compared to rats that do secrete vasopressin [18]. Further evidence supporting a detrimental role for vasopressin in renal disease progression can be derived from experimental studies using vasopressin receptor antagonists. These studies are summarized in table 1 , and are discussed in more detail in the section on vasopressin receptor antagonists.

\section{Human Evidence}

In humans, evidence for the potential deleterious role of vasopressin can be derived from observational data and from intervention studies inducing an increase or a decrease in vasopressin activity.

A retrospective analysis of data obtained in CKD patients participating in the MDRD study showed that higher urinary volume and lower estimated urinary os- molarity were associated with faster estimated GFR (eGFR) decline [31]. Two possible explanations for this relationship were offered. The first is that excessive fluid intake may cause faster renal disease progression. The other explanation is that, instead of the cause, a high urinary volume with a low urinary osmolarity is merely the result of faster renal disease progression, with vasopressin thus as an innocent bystander. In our opinion, there may be a third option: a high vasopressin level may have caused faster renal disease progression. One of the clinical manifestations of CKD is a defect in urinary concentrating ability [32]. Because of this concentrating defect, higher vasopressin levels can be expected to compensate for the urinary concentrating defect. These higher vasopressin levels may in turn be causally related in renal disease progression, as suggested by the aforementioned animal experiments. Unfortunately, vasopressin concentra- 


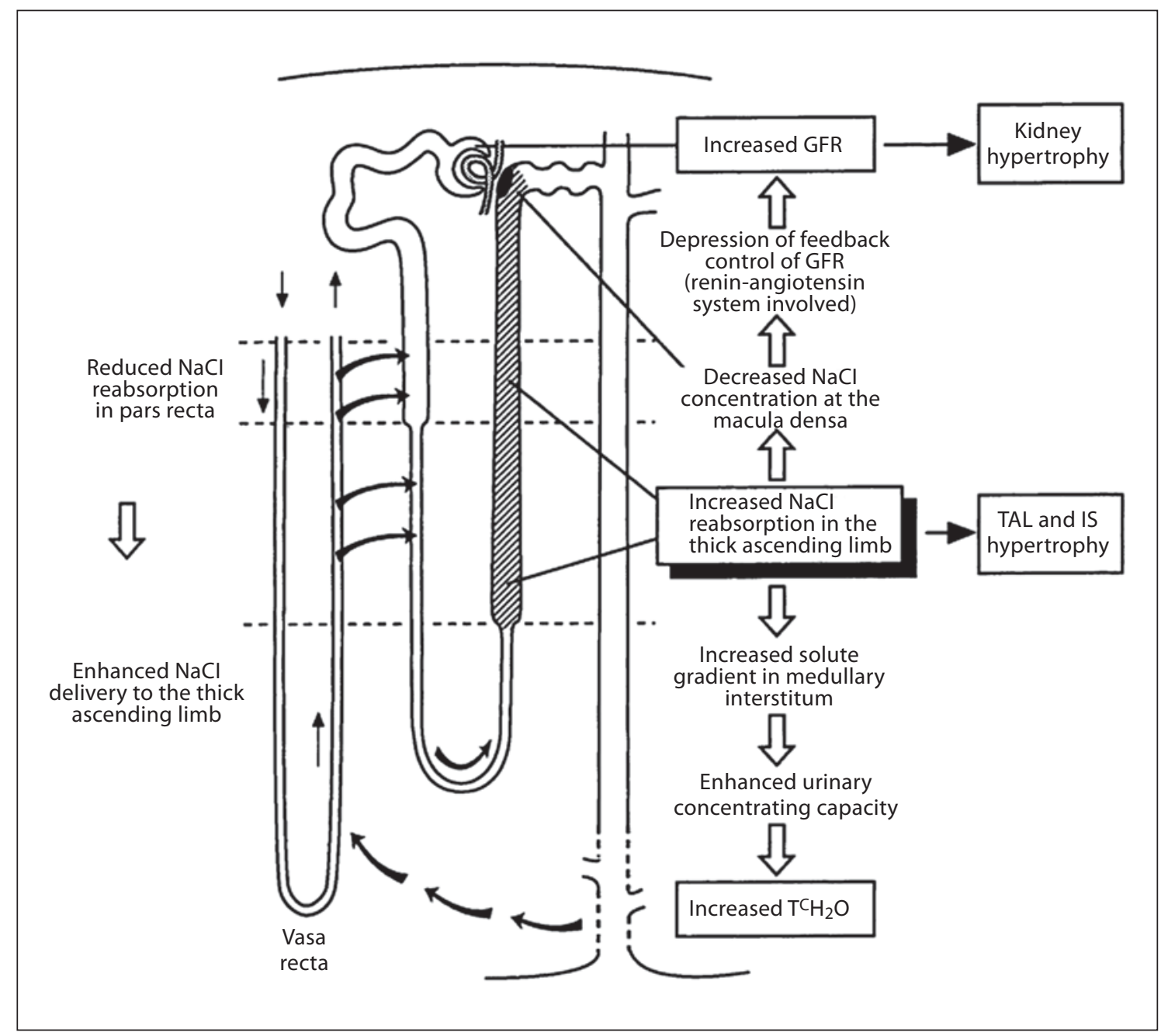

Fig. 1. Potential detrimental influence of vasopressin on the kidney. Proposed sequence of events, illustrating how intrarenal recycling of urea (arrows), triggered by vasopressin and essential to the urinary concentrating mechanism, might influence GFR indirectly by modifying the composition of the tubular fluid at the macula densa and thus the intensity of the tubuloglomerular feedback control of GFR. This might induce glomerular hyperfiltration on the short term. On the long term, this hyperfiltration will be detrimental (figure derived from Bankir and Kriz [10]). tion was not determined in the MDRD study. Definite conclusions on the role of vasopressin can therefore not be drawn upon these data.

In general, studies in humans on the association between endogenous vasopressin concentration and onset or progression of CKD are scarce. This may at least partially be caused by the fact that direct measurement of vasopressin is problematic. More than $90 \%$ of vasopressin in the circulation is bound to platelets [33], vasopressin is unstable in isolated plasma [34], and most vasopressin assays have relatively limited sensitivity. Recently, an assay has been developed to measure copeptin, the stable Cterminal portion of the precursor of vasopressin [35]. Copeptin has been shown to be a reliable marker of vasopressin secretion and appears to be a clinically helpful method for indirectly assessing vasopressin plasma concentration [36]. For these reasons, in more recent clinical research, copeptin is measured as a surrogate for vasopressin concentration.

In the PREVEND study, a large observational community-based population study, it was found that a high concentration of copeptin was associated with a low 
Fig. 2. Epidemiological evidence suggesting deleterious renal effects of vasopressin in 7,593 subjects participating in a general population screening. a Copeptin concentration (as a surrogate for vasopressin) was positively associated with the amount of urinary albumin excretion. $\mathbf{b}$ This association is as strong as the association between albuminuria and known risk factors for albuminuria [37]. UAE = Urinary albumin excretion; MAP = mean arterial pressure; $\mathrm{BMI}=$ body mass index.
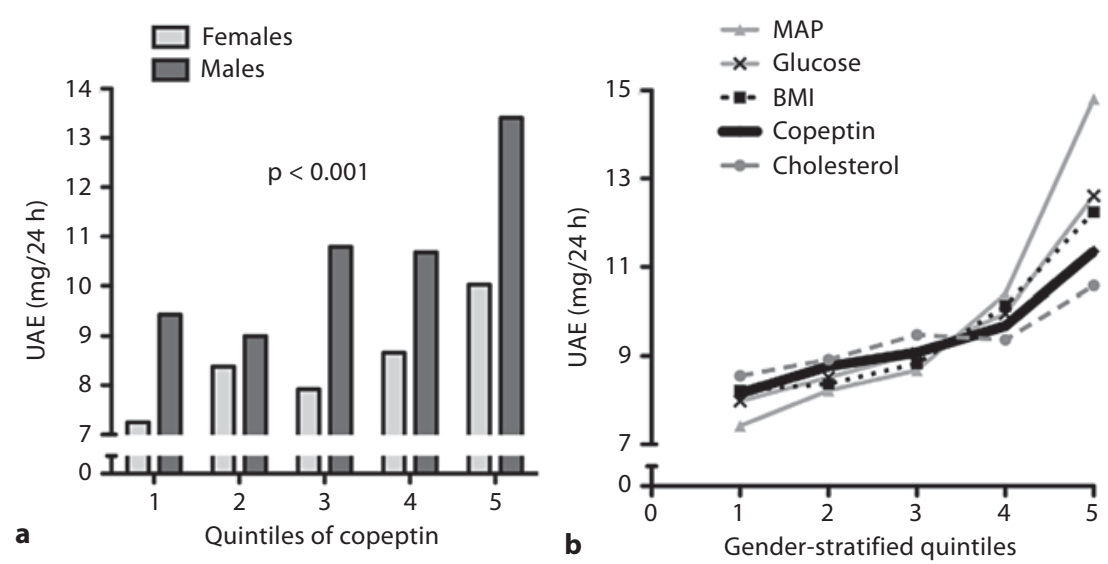

24-hour urinary volume and a high 24-hour urinary osmolarity, consistent with normal physiology [37]. Furthermore, this study showed that copeptin concentration was positively associated with the amount of urinary albumin excretion (fig. 2a), even after adjustment for potential confounders. The association between albuminuria and copeptin was as strong as the association between albuminuria and known risk factors for albuminuria such as BMI, glucose and cholesterol (fig. 2b). In patients with diabetes mellitus, both vasopressin and copeptin were found to be elevated $[38,39]$ and to be inversely associated with eGFR [40]. These cross-sectional observations are in line with the aforementioned experimental data showing that vasopressin promotes renal damage. Unfortunately, these studies did not investigate whether higher plasma copeptin levels predict eGFR loss.

This question was addressed in a study in 548 renal transplant recipients. It was shown that plasma concentration of copeptin predicted renal function loss over a 3.2-year follow-up period. This association was unmodified by adjustment for baseline eGFR, age, gender and other known risk factors for renal function decline in renal transplant recipients [41]. Similarly as in the PREVEND study, regulation and action of copeptin were consistent with normal physiology in this study, since at baseline a positive association between plasma osmolarity and copeptin concentration was found, as well as a negative association between copeptin and 24-hour urinary volume and fractional urea excretion, and a positive association between copeptin and urinary sodium concentration as a surrogate for urinary concentrating capacity (fig. 3).

Potential Deleterious Effects of VP in CKD and Particularly ADPKD
The most compelling evidence for a possible deleterious role of vasopressin in CKD can be derived from the pioneering experiments by Bankir et al. [42]. In 6 healthy volunteers, they showed that infusion of the vasopressin V2 receptor agonist desmopressin did not change creatinine and $\beta_{2}$-microglobulin excretion, but increased albuminuria markedly [42]. This suggests that the rise in albuminuria was due to an increased glomerular leakage of albumin. Desmopressin also increased albuminuria in patients with central diabetes insipidus and in patients with hereditary nephrogenic diabetes insipidus bearing aquaporin-2 mutations. However, albuminuria was not increased in patients with hereditary nephrogenic diabetes insipidus bearing mutations of the V2 receptor. As part of their experiment, rats were given ACE inhibitors and angiotensin-2 receptor blockers, which blunted the desmopressin-induced rise in albuminuria [42]. Given these data, the albuminuric effect of vasopressin seems to result from increased glomerular leakage, to require functional vasopressin V2 receptors, and to be mediated, at least in part, by the renin-angiotensin system.

\section{Particularly Deleterious in Autosomal Dominant Polycystic Kidney Disease?}

There is a relatively large body of experimental evidence suggesting that vasopressin may have a special deleterious role in the process of cyst growth and renal function decline in patients with autosomal dominant polycystic kidney disease (ADPKD). ADPKD is the most frequent hereditary kidney disease, characterized by cyst formation leading to kidney enlargement and renal failure. Activation of the vasopressin V2 receptor 
Fig. 3. Clinical evidence suggesting deleterious renal effects of vasopressin in renal transplant recipients $(\mathrm{n}=548)$. Copeptin plasma concentration (as a surrogate for vasopressin) is associated with 24-hour urinary volume (a), urinary sodium concentration (b) and fractional urea excretion at baseline (c), and predicts renal function decline during follow-up (median 3.2 years) (d) [41].

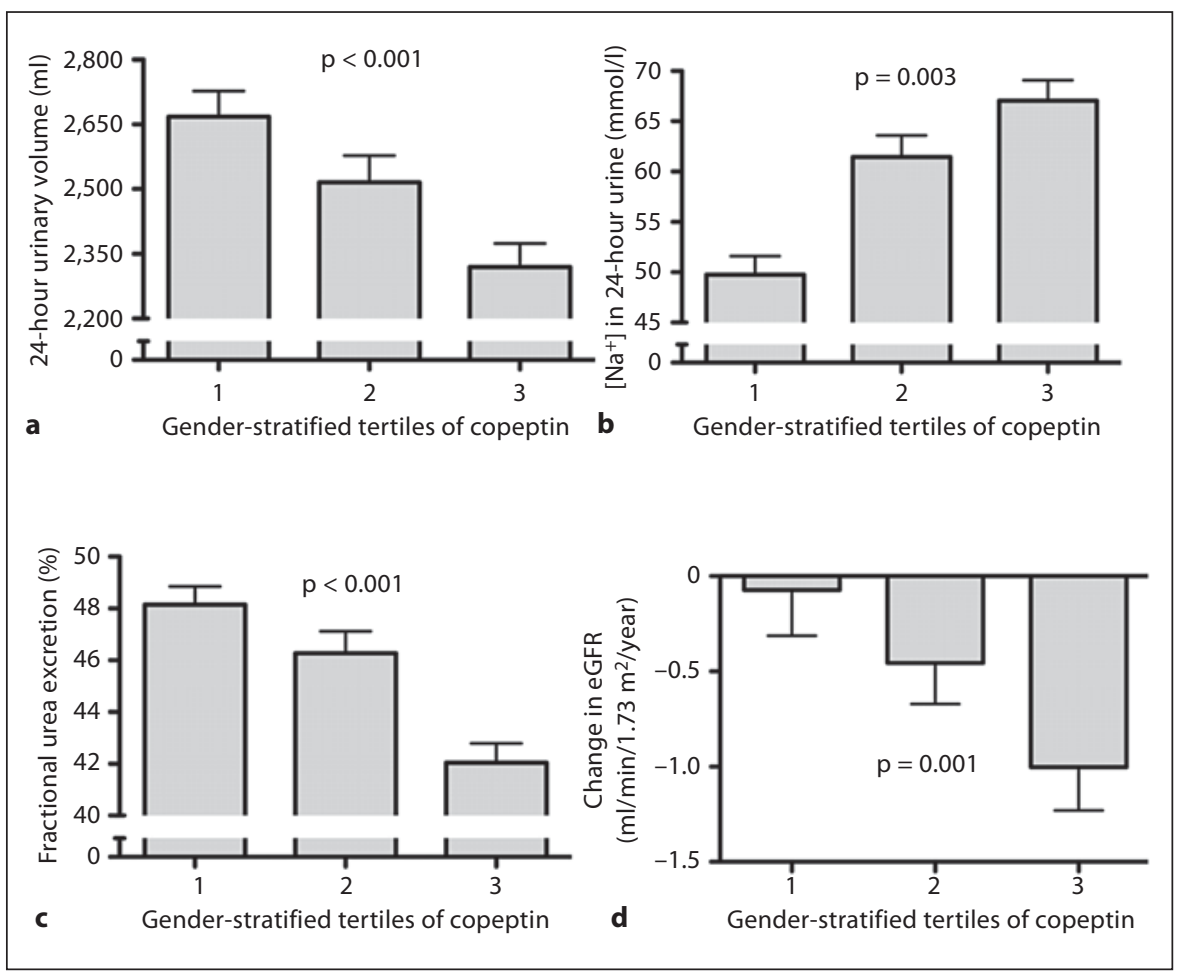

in renal collecting duct cells results in an increase in cAMP, which in the normal situation is inhibited by a calcium influx in the cell. In ADPKD, however, this process is not adequately inhibited. Mutations in the $p k d 1$ or $p k d 2$ gene cause a dysfunctional polycystin complex, inducing a decrease in intracellular calcium. As a result, intracellular cAMP rises, leading to cell proliferation and cyst fluid secretion, and consequently to cyst growth [43]. Furthermore, in animal models for ADPKD, vasopressin is elevated and V2 receptor expression upregulated $[44,45]$.

Subjects with ADPKD have a defect in urinary concentrating capacity. Gabow et al. [46] showed that this defect is already present early in the disease and parallels renal anatomical disruption by cysts: the more cysts, the more impaired the concentrating capacity. This suggests that ADPKD patients will have higher vasopressin levels to maintain fluid balance. Unfortunately, this study did not measure vasopressin or copeptin levels. This was done in a study we performed in 102 ADPKD patients at different stages of their disease [47]. Higher copeptin levels were associated with more albuminuria, larger kidneys, lower renal blood flow and reduced GFR (fig. 4). These associations were similar in males and females, and independent of potential confounders. In these AD-
PKD patients, plasma osmolarity was positively associated with copeptin, as expected. In contrast to the aforementioned studies in the general population [37] and renal transplant recipients [41], copeptin concentration was however not associated with 24-hour urinary volume, 24 hour urinary osmolarity or fractional urea excretion. This suggests that in ADPKD patients, vasopressin may not have the same physiologic consequences as in healthy subjects and renal transplant recipients.

Taking these data into consideration, we formulated a hypothesis of how vasopressin might be causally involved in the final common pathway of GFR decline in CKD in general, and in ADPKD in particular. In subjects with lower GFR, interstitial fibrosis due to loss of functioning nephrons will impair the normal medullary urea gradient. These subjects have therefore an impaired urinary concentrating capacity and consequently lower urinary osmolarity and higher urinary volume than subjects with normal renal function $[48,49]$. Higher vasopressin levels will be necessary to maintain fluid balance. Patients with ADPKD have an additional anatomical disruption of the medullary architecture induced by cyst formation, which will also negatively affect the urea gradient and consequently diminish urinary concentrating capacity. According to this hypothesis, genetically determined pro- 
Fig. 4. Clinical evidence suggesting deleterious renal effects of vasopressin in ADPKD patients $(n=102$; males $=\boldsymbol{\Delta}$ and _- , females $=\bigcirc$ and --------). Copeptin plasma concentration (as a surrogate for vasopressin) is associated with various markers of ADPKD severity [47]. TRV = Total renal volume (a); UAE = urinary albumin excretion (c); ERBF = effective renal blood flow (b).
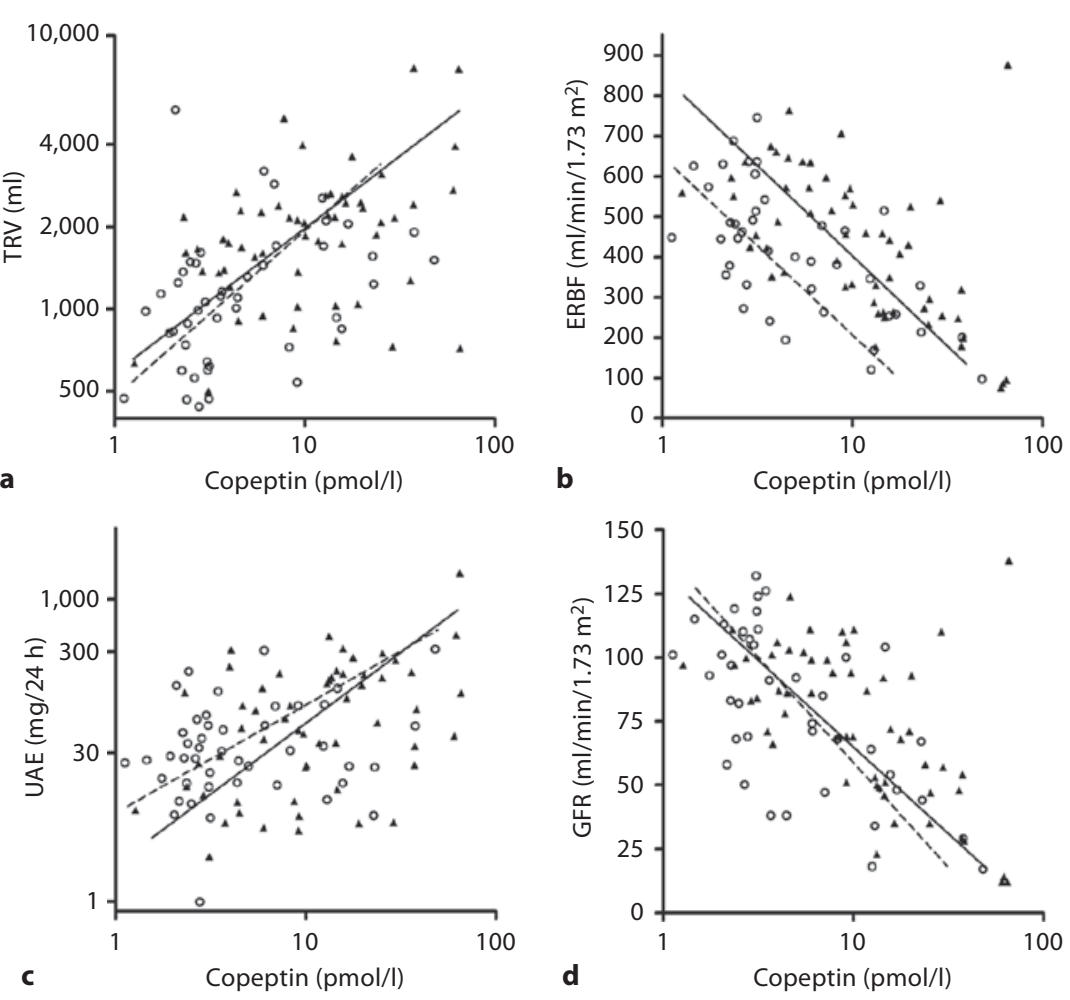

gressive cyst formation will lead to impaired water reabsorption, in turn leading to higher vasopressin concentration. At the same time, these higher vasopressin levels will result in disease progression via mechanisms discussed in the section on the deleterious effects of vasopressin. These processes induce a vicious circle predisposing to further cyst growth, distortion of renal anatomy and renal function decline. Figure 5 depicts this hypothesis schematically.

\section{The Renoprotective Potential for Vasopressin Receptor Antagonists}

\section{In Chronic Kidney Disease}

In the last two decades, several vasopressin antagonists have been developed. These drugs will provide the possibility to prove whether vasopressin is causally involved in renal disease progression. Several experimental studies have shown that V1a or V2 receptor antagonists, or both in combination, have a renoprotective effect in CKD (table 1). In a recent study, treatment with a dual V1a and V2 receptor antagonist, initiated 3 weeks after

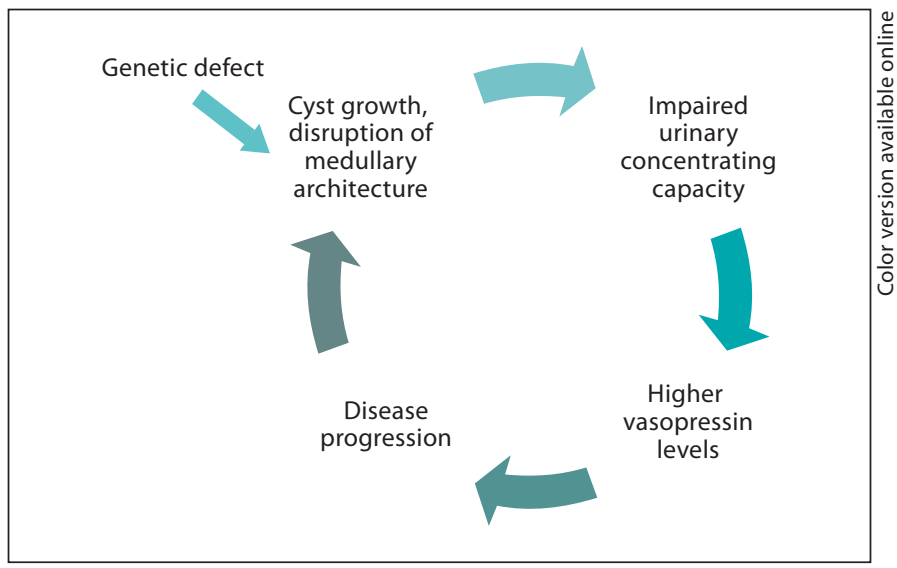

Fig. 5. Schematic representation of the vicious circle by which vasopressin may lead to progressive renal function loss.

5/6 nephrectomy, lowered blood pressure, proteinuria and glomerular sclerosis in Sprague-Dawley rats [50]. This effect was comparable to that of an ACE inhibitor or an angiotensin-2 receptor blocker. The combination of the vasopressin antagonist with an ACE inhibitor or an- 
Table 2. Experimental studies investigating a renal protective role of vasopressin receptor antagonists in polycystic diseases

\begin{tabular}{|c|c|c|c|}
\hline Study & Class of drug & Animal model & Results \\
\hline $\begin{array}{l}\text { Gattone et al. } \\
{[45], 2003}\end{array}$ & V2RA & $\begin{array}{l}\text { PCK rats } \\
\text { (model for ARPKD) }\end{array}$ & $\begin{array}{l}\text { reduced renal cAMP levels, inhibited disease progression, } \\
\text { reduced systolic blood pressure }\end{array}$ \\
\hline $\begin{array}{l}\text { Gattone et al. } \\
{[45], 2003}\end{array}$ & V2RA & $\begin{array}{l}\mathrm{CD} 1 / p c y \text { mice } \\
\text { (model for nephronophthisis) }\end{array}$ & $\begin{array}{l}\text { inhibited renal accumulation cAMP and decreased disease } \\
\text { development }\end{array}$ \\
\hline $\begin{array}{l}\text { Wang et al. } \\
{[51], 2005}\end{array}$ & V2RA & $\begin{array}{l}\text { PCK rats } \\
\text { (model for ARPKD) }\end{array}$ & reduced renal cAMP levels, fibrosis, and kidney weight \\
\hline $\begin{array}{l}\text { Meijer et al. } \\
\text { [52], } 2011\end{array}$ & V2RA & $\begin{array}{l}\text { PKD1 mice } \\
\text { (model for ADPKD1) }\end{array}$ & $\begin{array}{l}\text { reduced cyst formation and kidney weight after } 3 \text { weeks' admin- } \\
\text { istration; after } 6 \text { weeks effects were not significant anymore }\end{array}$ \\
\hline
\end{tabular}

$\mathrm{V}=$ Vasopressin; RA = receptor antagonist; ADPKD2 = autosomal dominant polycystic kidney disease caused by a mutation in the $p k d 2$ gene; ADPKD1 = autosomal dominant polycystic kidney disease caused by a mutation in the $p k d 1$ gene.

giotensin-2 receptor blocker, however, did not offer significantly more renoprotection. This suggests that part of the renoprotective effect of vasopressin antagonism is mediated by the renin-angiotensin system.

\section{In ADPKD}

Vasopressin V2 receptor antagonists have been shown to reduce cyst growth and preserve renal function in various animal models for polycystic kidney disease. These studies are summarized in table 2 .

In human ADPKD, Torres et al. [53] analyzed data of a dose-ranging study monitoring long-term effects of the vasopressin V2 receptor antagonist tolvaptan. Forty-six patients were randomized 1:1 to open-label, low dose $(45 / 15 \mathrm{mg})$ or medium dose $(60 / 30 \mathrm{mg})$ of this drug. Their data suggest that the medium dose of tolvaptan during 3 years of follow-up slowed cyst growth and renal function deterioration when compared to the low dose. A large, phase 3, double-blind, placebo-controlled clinical trial is currently being conducted in patients with ADPKD with the same vasopressin V2 receptor antagonist, the TEMPO 3/4 study. This trial includes 1,445 patients with $\mathrm{AD}$ PKD who have relatively preserved renal function at baseline (estimated creatinine clearance $\geq 60 \mathrm{ml} / \mathrm{min}$ ), but are anticipated to have progressive renal disease given the inclusion criterion of a large total kidney volume $(\geq 750 \mathrm{ml})$. The primary outcome is the difference in growth rate in total kidney volume for tolvaptan compared to placebo. Secondary outcome parameters include time to multiple ADPKD progression events, such as time to a $33 \%$ change in serum creatinine or increase in albuminuria [54].

\section{V1a versus V2 Blockade}

The observation in animal models that blockade of both the V1a and the V2 receptor offers renoprotection suggests that stimulation of both receptors contributes to progression of CKD. The relative contributions of the $\mathrm{V} 2$ and V1a receptors, however, are ill defined. The dissection of V1a- and V2-dependent effects may become an important topic. Due to pharmacological blockade of the V2 receptor, a compensatory rise in vasopressin plasma levels is expected. In animal experiments, the rise in vasopressin is substantial [52], whereas in humans it has been described to be mild and within the physiological range. Whether this increase in vasopressin may have deleterious or beneficial effects on the unblocked V1a (and V1b) receptors is yet unknown and this question needs to be addressed in future (clinical) studies. Of note, an effect on both receptors simultaneously can theoretically also be obtained by decreasing plasma vasopressin levels by means of increasing fluid intake. However, in order to achieve effective vasopressin suppression, fluid intake should be increased to obtain a urinary osmolarity of less than $300 \mathrm{mosmol} / \mathrm{l}$. Dependent on sodium and protein intake, this implies increasing fluid intake to at least 4-6 liters per day. Whether adherence to such an advice is feasible for prolonged periods of time is questionable. 


\section{Conclusion}

Vasopressin has a crucial role in water homeostasis by regulating free water clearance. Despite this essential role for normal physiology, an increasing body of evidence suggests that vasopressin also contributes to CKD progression. Plasma vasopressin levels are elevated in CKD animal models, as well as in patients with diabetic and nondiabetic nephropathies. Suppression of vasopressin activity ameliorates glomerulosclerosis and tubulointer- stitial fibrosis in CKD models. Particularly in ADPKD, the most prevalent hereditary kidney disease, vasopressin is thought to have a pathophysiological role. The evidence for a detrimental role of vasopressin in CKD and the availability of vasopressin receptor antagonists allude to the possibility that these drugs may form a valuable addition to the current treatment armamentarium to attenuate renal function decline in patients with CKD in general, and in ADPKD in particular.

\section{References}

$>1$ Robertson GL, Athar S: The interaction of blood osmolality and blood volume in regulating plasma vasopressin in man. J Clin Endocrinol Metab 1976;42:613-620.

$>2$ Mutig K, Paliege A, Kahl T, Jons T, MullerEsterl W, Bachmann S: Vasopressin V2 receptor expression along rat, mouse, and human renal epithelia with focus on TAL. Am J Physiol Renal Physiol 2007;293:F1166F1177.

-3 Aoyagi T, Izumi Y, Hiroyama M, Matsuzaki T, Yasuoka Y, Sanbe A, Miyazaki H, Fujiwara Y, Nakayama Y, Kohda Y, Yamauchi J, Inoue T, Kawahara K, Saito H, Tomita K, Nonoguchi $\mathrm{H}$, Tanoue A: Vasopressin regulates the renin-angiotensin-aldosterone system via V1a receptors in macula densa cells. Am J Physiol Renal Physiol 2008;295:F100-F107.

$\checkmark 4$ Bankir L: Antidiuretic action of vasopressin: quantitative aspects and interaction between V1a and V2 receptor-mediated effects. Car diovasc Res 2001;51:372-390.

5 Perucca J, Bichet DG, Bardoux P, Bouby N, Bankir L: Sodium excretion in response to vasopressin and selective vasopressin receptor antagonists. J Am Soc Nephrol 2008;19: 1721-1731.

6 Gillies GE, Linton EA, Lowry PJ: Corticotropin releasing activity of the new CRF is potentiated several times by vasopressin. Nature 1982;299:355-357.

7 Rivier C, Vale W: Modulation of stress-induced ACTH release by corticotropin-releasing factor, catecholamines and vasopressin. Nature 1983;305:325-327.

$>8$ Pedersen NB, Hofmeister MV, Rosenbaek LL, Nielsen J, Fenton RA: Vasopressin induces phosphorylation of the thiazide-sensitive sodium chloride cotransporter in the distal convoluted tubule. Kidney Int 2010;78:160169.

9 Bankir L, Fernandes S, Bardoux P, Bouby N, Bichet DG: Vasopressin-V2 receptor stimulation reduces sodium excretion in healthy humans. J Am Soc Nephrol 2005;16:19201928.
10 Bankir L, Kriz W: Adaptation of the kidney to protein intake and to urine concentrating activity: similar consequences in health and CRF. Kidney Int 1995;47:7-24.

11 Bouby N, Ahloulay M, Nsegbe E, Dechaux M, Schmitt F, Bankir L: Vasopressin increases glomerular filtration rate in conscious rats through its antidiuretic action. J Am Soc Nephrol 1996;7:842-851.

12 Bardoux P, Martin H, Ahloulay M, Schmitt F, Bouby N, Trinh-Trang-Tan MM, Bankir L: Vasopressin contributes to hyperfiltration, albuminuria, and renal hypertrophy in diabetes mellitus: study in vasopressin-deficient Brattleboro rats. Proc Natl Acad Sci USA 1999;96:10397-10402.

13 Bankir L, Bichet DG, Bouby N: Vasopressin $\mathrm{V} 2$ receptors, $\mathrm{ENaC}$, and sodium reabsorption: a risk factor for hypertension? Am J Physiol Renal Physiol 2010;299:F917-F928.

14 Tahara A, Tsukada J, Tomura Y, Suzuki T, Yatsu T, Shibasaki M: Effect of YM218, a nonpeptide vasopressin $\mathrm{V}(1 \mathrm{~A})$ receptor-selective antagonist, on rat mesangial cell hyperplasia and hypertrophy. Vascul Pharmacol 2007;46:463-469.

15 Tahara A, Tsukada J, Tomura Y, Yatsu T, Shibasaki M: Vasopressin increases type IV collagen production through the induction of transforming growth factor-beta secretion in rat mesangial cells. Pharmacol Res 2008; 57:142-150.

16 Bouby N, Bachmann S, Bichet D, Bankir L: Effect of water intake on the progression of chronic renal failure in the 5/6 nephrectomized rat. Am J Physiol 1990;258:F973F979.

17 Sugiura T, Yamauchi A, Kitamura H, Matsuoka Y, Horio M, Imai E, Hori M: High water intake ameliorates tubulointerstitial injury in rats with subtotal nephrectomy: possible role of TGF-beta. Kidney Int 1999;55: 1800-1810.

18 Bouby N, Hassler C, Bankir L: Contribution of vasopressin to progression of chronic renal failure: study in Brattleboro rats. Life Sci 1999;65:991-1004.
-19 Naito A, Hasegawa H, Kurasawa T, Ohtake Y, Matsukawa H, Ezure Y, Koike K, Shigenobu K: Histopathological study of kidney abnormalities in an experimental SIADH rat model and its application to the evaluation of the pharmacologic profile of VP-343, a selective vasopressin $\mathrm{V} 2$ receptor antagonist. Biol Pharm Bull 2001;24:897-901.

20 Fernandes S, Bruneval P, Hagege A, Heudes D, Ghostine S, Bouby N: Chronic V2 vasopressin receptor stimulation increases basal blood pressure and exacerbates deoxycorticosterone acetate-salt hypertension. Endocrinology 2002;143:2759-2766.

21 Torres VE: Vasopressin in chronic kidney disease: an elephant in the room? Kidney Int 2009;76:925-928.

22 Okada H, Suzuki H, Kanno Y, Yamamura Y, Saruta T: Effects of vasopressin V1 and V2 receptor antagonists on progressive renal failure in rats. Clin Sci (Lond) 1994;86:399404.

23 Okada H, Suzuki H, Kanno Y, Yamamura Y, Saruta T: Chronic and selective vasopressin blockade in spontaneously hypertensive rats. Am J Physiol 1994;267:R1467-R1471.

24 Okada H, Suzuki H, Kanno Y, Saruta T: Effects of novel, nonpeptide vasopressin antagonists on progressive nephrosclerosis in rats. J Cardiovasc Pharmacol 1995;25:847-852.

25 Okada H, Suzuki H, Kanno Y, Saruta T: Evidence for the involvement of vasopressin in the pathophysiology of adriamycin-induced nephropathy in rats. Nephron 1996;72:667672

-26 Kurihara I, Saito T, Obara K, Shoji Y, Hirai M, Soma J, Sato H, Imai Y, Abe K: Effect of a nonpeptide vasopressin $\mathrm{V} 1$ antagonist (OPC-21268) on experimental accelerated focal glomerulosclerosis. Nephron 1996;73: 629-636.

27 Bardoux P, Bruneval P, Heudes D, Bouby N, Bankir L: Diabetes-induced albuminuria: role of antidiuretic hormone as revealed by chronic V2 receptor antagonism in rats. Nephrol Dial Transplant 2003;18:1755-1763. 
$\checkmark 28$ Windt WA, Tahara A, Kluppel AC, De Zeeuw D, Henning RH, van Dokkum RP: Early, but not late therapy with a vasopressin Vla-antagonist ameliorates the development of renal damage after 5/6 nephrectomy. J Renin Angiotensin Aldosterone Syst 2006;7:217224.

29 Okada T, Sakaguchi T, Hatamura I, Saji F, Negi S, Otani H, Muragaki Y, Kawachi H, Shigematsu T: Tolvaptan, a selective oral vasopressin V2 receptor antagonist, ameliorates podocyte injury in puromycin aminonucleoside nephrotic rats. Clin Exp Nephrol 2009;13:438-446.

- 30 Perico N, Zoja C, Corna D, Rottoli D, Gaspari F, Haskell L, Remuzzi G: V1/V2 vasopressin receptor antagonism potentiates the renoprotection of renin-angiotensin system inhibition in rats with renal mass reduction. Kidney Int 2009;76:960-967.

- 31 Hebert LA, Greene T, Levey A, Falkenhain ME, Klahr S: High urine volume and low urine osmolality are risk factors for faster progression of renal disease. Am J Kidney Dis 2003;41:962-971.

-32 Bricker NS, Dewey RR, Lubowitz H, Stokes J, Kirkensgaard T: Observations on the concentrating and diluting mechanisms of the diseased kidney. J Clin Invest 1959;38:516523.

-33 Preibisz JJ, Sealey JE, Laragh JH, Cody RJ, Weksler BB: Plasma and platelet vasopressin in essential hypertension and congestive heart failure. Hypertension 1983;5:I129I138.

34 Robertson GL, Mahr EA, Athar S, Sinha T: Development and clinical application of a new method for the radioimmunoassay of arginine vasopressin in human plasma. J Clin Invest 1973;52:2340-2352.

- 35 Morgenthaler NG, Struck J, Alonso C, Bergmann A: Assay for the measurement of copeptin, a stable peptide derived from the precursor of vasopressin. Clin Chem 2006;52: $112-119$.

36 Morgenthaler NG, Struck J, Jochberger S, Dunser MW: Copeptin: clinical use of a new biomarker. Trends Endocrinol Metab 2008; 19:43-49.
37 Meijer E, Bakker SJ, Halbesma N, de Jong PE, Struck J, Gansevoort RT: Copeptin, a surrogate marker of vasopressin, is associated with microalbuminuria in a large population cohort. Kidney Int 2010;77:29-36.

38 Zerbe RL, Vinicor F, Robertson GL: Plasma vasopressin in uncontrolled diabetes mellitus. Diabetes 1979;28:503-508.

39 Enhorning S, Wang TJ, Nilsson PM, Almgren P, Hedblad B, Berglund G, Struck J, Morgenthaler NG, Bergmann A, Lindholm E, Groop L, Lyssenko V, Orho-Melander M, NewtonCheh C, Melander O: Plasma copeptin and the risk of diabetes mellitus. Circulation 2010;121:2102-2108.

40 Maier C, Clodi M, Neuhold S, Resl M, Elhenicky M, Prager R, Moertl D, Strunk G, Luger A, Struck J, Pacher R, Hulsmann M: Endothelial markers may link kidney function to cardiovascular events in type 2 diabetes. Diabetes Care 2009;32:1890-1895.

41 Meijer E, Bakker SJ, de Jong PE, Homan van der Heide JJ, van Son WJ, Struck J, Lems SP, Gansevoort RT: Copeptin, a surrogate marker of vasopressin, is associated with accelerated renal function decline in renal transplant recipients. Transplantation 2009;88: 561-567.

42 Bardoux P, Bichet DG, Martin H, Gallois Y, Marre M, Arthus MF, Lonergan M, Ruel N, Bouby N, Bankir L: Vasopressin increases urinary albumin excretion in rats and humans: involvement of $\mathrm{V} 2$ receptors and the renin-angiotensin system. Nephrol Dial Transplant 2003; 18:497-506.

43 Belibi FA, Reif G, Wallace DP, Yamaguchi T, Olsen L, Li H, Helmkamp GM Jr, Grantham JJ: Cyclic AMP promotes growth and secretion in human polycystic kidney epithelial cells. Kidney Int 2004;66:964-973.

44 Torres VE, Wang X, Qian Q, Somlo S, Harris PC, Gattone VH: Effective treatment of an orthologous model of autosomal dominant polycystic kidney disease. Nat Med 2004;10: 363-364.

45 Gattone VH, Wang X, Harris PC, Torres VE: Inhibition of renal cystic disease development and progression by a vasopressin V2 receptor antagonist. Nat Med 2003;9:13231326.

-46 Gabow PA, Kaehny WD, Johnson AM, Duley IT, Manco-Johnson M, Lezotte DC, Schrier RW: The clinical utility of renal concentrating capacity in polycystic kidney disease. Kidney Int 1989;35:675-680.
47 Meijer E, Bakker SJ, van der Jagt EJ, Navis G, de Jong PE, Struck J, Gansevoort RT: Copeptin, a surrogate marker of vasopressin, is associated with disease severity in autosomal dominant polycystic kidney disease. Clin J Am Soc Nephrol 2011;6:361-368.

48 Tannen RL, Regal EM, Dunn MJ, Schrier RW: Vasopressin-resistant hyposthenuria in advanced chronic renal disease. N Engl J Med 1969;280:1135-1141.

49 Garcia Nieto VM, Yanes MI, Zamorano MM, Gonzalez MJ, Aros CP, Garin EH: Renal concentrating capacity as a marker for glomerular filtration rate. Acta Paediatr 2008;97:96-99.

50 Perico N, Zoja C, Corna D, Rottoli D, Gaspari F, Haskell L, Remuzzi G: V1/V2 vasopressin receptor antagonism potentiates the renoprotection of renin-angiotensin system inhibition in rats with renal mass reduction. Kidney Int 2009;76:960-967.

-51 Wang X, Gattone V, Harris PC, Torres VE: Effectiveness of vasopressin $\mathrm{V} 2$ receptor antagonists OPC-31260 and OPC-41061 on polycystic kidney disease development in the PCK rat. J Am Soc Nephrol 2005;16:846-851.

52 Meijer E, Gansevoort RT, de Jong PE, Wal A, Leonhard WN, de Krey S, Goor H, de Heer E, Born J, Peters DJ: Vasopressin V2 receptor antagonism in autosomal dominant polycystic kidney disease: optimal timing and dosing of the drug. Nephrol Dial Transplant 2011, E-pub ahead of print.

53 Torres VE, Chapman AB, Grantham JJ, Watnick TJ, Ouyang J, Krasa HB, Czerwiec FS: TEMPO 2/4 update: changes in ADPKD total kidney volume and eGFR with 3 years of tolvaptan and after withdrawal. Abstract ASN 2010:F-PO1822.

54 Torres VE, Meijer E, Bae KT, Chapman A, Devuyst O, Gansevoort RT, Grantham JJ, Higashihara E, Perrone RD, Krasa HB, Ouyang J, Czerwiec F: Rationale and design of the TEMPO (Tolvaptan Efficacy and Safety in Management of Autosomal Dominant Polycystic Kidney Disease and its Outcomes) 3-4 study. Am J Kidney Dis 2011, E-pub ahead of print. 